\section{Kodokan Judo Throwing Techniques}

por Toshiro Daigo

Kodansha International, 2005

288 páginas, $26 \times 19 \mathrm{~cm}$. Ilustraciones

I.S.B.N.: 4-7700-2330-8 • \$40.00

Disponible en:

Kodansha International Inc

c/o Oxford University Press

2001Evans Road • Cary, NC 27513

Tel: (800) 451.7556

Fax: (991) 677.1303

http://www.thejapanpage.com/

Idioma: Inglés

\section{Revisión por S. Biron Ebell}

Este puede ser el texto definitivo de las técnicas de proyección (nage waza) del Judo Kodokan. No sólo porque el libro esté bellamente diseñado, profusamente ilustrado con 1800 ilustraciones (que yo no he contado) y detallado técnicamente, sino también porque su autor es uno de los practicantes de judo más preeminentes a nivel mundial. Toshiro Daigo es $9^{\circ}$ dan, jefe del departamento de enseñanza y director técnico del Kodokan, el "hogar" del judo.

Habiendo transcurrido un periodo de gestación de más de ocho años hasta llegar a su forma final, ha merecido la pena esperar este libro. En palabras del autor: "El objetivo de este libro es proporcionar una correcta comprensión de la terminología de la técnica (waza) y su clasificación para el rico y siempre cambiante nage-waza en el shiai (competición) y en el randori (práctica libre)" y es el producto de un "laborioso esfuerzo”. Esta última afirmación es claramente evidente. El libro proporciona ajustadas descripciones y definiciones de las 67 nage waza del Kodokan. Clarifica la nomenclatura contemporánea y el conjunto de variantes aceptadas en cada waza, así como el contexto histórico para la mayoría de estas técnicas.

El libro contiene una breve introducción, una concisa sección titulada "Cinco puntos a considerar", y cinco capítulos de fotografías y descripciones técnicas. Existen cinco grandes clases de técnicas de proyección: mano (te), cadera o cintura (koshi), pie y pierna (ashi), técnicas que se ejecutan cayendo directamente sobre la propia espalda (ma-sutemi) y técnicas que se ejecutan cuando se cae sobre el propio costado (yoko-sutemi). Cada capítulo se centra en cada uno de estos grupos, ilustrando y describiendo 15 te, 11 koshi, 21 ashi, 4 ma-sutemi, y 15 yoko-sutemi. Cada técnica se presenta cuidadosamente en su forma básica junto con las variaciones aceptadas dentro de la propia definición de la técnica "... fijadas oficialmente por el Kodokan (p. 10)”. Se detallan con precisión los puntos clave de cada técnica y, a menudo, los de sus variantes. En algunos casos las diferencias entre técnicas son mínimas, pero el criterio de diferenciación es claro. También se incluyen cuatro técnicas que no se permiten en la competición ni en la práctica libre. Algunas técnicas son representadas y descritas tal y como se ejecutan formalmente en la kata (forma).

Al final de las descripciones más técnicas se ubican unos "puntos a considerar" que contienen comentarios sobre el origen histórico, la evolución de las técnicas y otras informaciones anecdóticas. Diseminadas por el libro hay joyas fascinantes de interpretación e información sobre el judo. Por ejemplo, en la página 107, Daigo bosqueja someramente tres conceptos relacionados con la iniciativa en el combate que se relacionan con la sincronización del ataque y del contraataque: sensen no sen, sen, y go no sen. Para encontrar estas joyas casi se requiere que uno lea el libro "de cabo a rabo", algo que puede que no suceda muy a menudo. No obstante, de hecho, el libro tiene una fácil lectura.

Este es el segundo libro de judo (hasta donde yo conozco) que traduce Françoise White (el otro es Canon of Judo, por Mifune). Su inglés es conciso, exacto, económico y culto, haciendo que los aspectos técnicos de cada técnica y las ilustraciones que los acompañan sean fáciles de entender.

Son muy pocos los defectos del libro. Los "Cinco puntos a considerar" (págs. 8-10) son para mí un tanto confusos. Un ejemplo de esto es: "No está permitido aplicar shime-waza (técnicas de estrangulación)... en el randori..." (p. 9). Por supuesto, esto no es cierto, desde el momento en que las estrangulaciones están presentes en la práctica libre y en la competición. Sin embargo, la mayoría de practicantes de judo avanzados llegarán a entender los cinco puntos después de una lectura detallada. Estos puntos son importantes como medios para comprender la historia, evolución y desarrollo curricular del judo, y, lo que es más importante, definen la lógica del propio libro.

Hay algunos errores editoriales que son probablemente problemas del "cortar y pegar”. Algunos párrafos se escapan de las descripciones técnicas que los preceden, sin existir una correcta ubicación del nombre de la nueva técnica que se discute. Estos problemas desmejoran más bien poco el texto ya que los practicantes de judo con experiencia reconocerán el error cuando consulten las ilustraciones de referencia.

Habría sido deseable un buen índice para ayudar a ordenar las muchas técnicas que se discuten y sus nombres alternativos (algunos ya en desuso) y para encontrar algunas informaciones importantes diseminadas en el texto. Del mismo modo, una bibliografía que recoja el conjunto de referencias citadas es necesaria, incluso si la mayor parte de las referencias son japonesas.

Este libro en una aportación trascendental a la literatura sobre judo. Las definiciones y las descripciones técnicas de las proyecciones proporcionan modelos de enseñanza para cualquier profesor serio. Asimismo, la taxonomía que se presenta facilita una identificación exacta de las técnicas usadas durante la práctica libre y la competición. Este libro aumenta apropiadamente el Kodokan Judo de Kano, y el Canon of Judo de Mifune.

\section{Referencias}

Kano, J. (1986). Kodokan Judo. Tokyo: Kodansha International.

Mifune, K. (2004). Canon of Judo. Tokyo: Kodansha International.

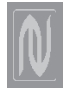

